\title{
Dynamics of Urbanization and Its Impact on Land-Use/Land-Cover: A Case Study of Megacity Delhi
}

\author{
Manju Mohan ${ }^{1 *}$, Subhan K. Pathan ${ }^{2}$, Kolli Narendrareddy ${ }^{1}$, Anurag Kandya ${ }^{1}$, Sucheta Pandey ${ }^{3}$ \\ ${ }^{1}$ Centre for Atmospheric Sciences, Indian Institute of Technology, New Delhi, India; ${ }^{2}$ Indian Space Research Organisation, Space \\ Applications Centre, Ahmedabad, India; ${ }^{3}$ Centre of Studies in Resource Engineering Indian Institute of Technology Bombay, Mum- \\ bai, India. \\ Email: ${ }^{*}$ mmohan66@gmail.com, ${ }^{*}$ mmohan6@hotmail.com
}

Received July $12^{\text {th }}, 2011$; revised September $6^{\text {th }}, 2011$; accepted October $11^{\text {th }}, 2011$.

\begin{abstract}
The rapid expansion of urban areas due to rise in population and economic growth is increasing additional demand on natural resources thereby causing land-use changes especially in megacities. Therefore, serious problems associated with rapid development such as additional infrastructure, informal settlements, environmental pollution, destruction of ecological structure and scarcity of natural resources has been studied carefully using remote sensing and GIS technologies for a rapidly grown megacity namely, Delhi. The present work evaluates the land use/land cover (LULC) changes and urban expansion in Mega city Delhi and highlights the major impact of rapid urbanization and population growth on the land cover changes which needs immediate attention. The results indicate that the city is expanding towards its peripheral region with the conversion of rural regions in to urban expansions. Built-up area of Delhi witnessed an overall increment from $540.7 \mathrm{~km}^{2}$ to $791.96 \mathrm{~km}^{2}$ or $16.86 \%$ of the total city area $\left(1490 \mathrm{~km}^{2}\right)$ during the study period 1997 to 2008 which mainly came from agriculture land, waste land, scrub-land, sandy areas and water bodies. The increment in forest cover of $0.5 \%$ is very small when considering the increment in built up category to $17 \%$. Total area of waterbodies has reduced by 52.9\% in a ten year period (58.26 km in 1997 to $27.43 \mathrm{~km}^{2}$ in 2008) with shallow waterbodies now having a dismal presence. LULC changes are studied with the urban growth parameters such as population, vehicles, gross state domestic product etc. The results lay emphasis on the concepts of urban planning to be applied such that more consideration is towards the preservation and management of natural land use classes which will increase the quality of life in an urban environment.
\end{abstract}

Keywords: Satellite Imagery, Landuse-Landcover Distribution, Urban Planning, Built-Up Areas, Urban Growth Parameters, Change Detection

\section{Introduction}

Urbanization is a gift to the human society if it is controlled, coordinated and planed. However, unplanned urbanization is a curse. In 2008 more than half of the world's population were urban dwellers and the urban population is expected to reach $81 \%$ by 2030 [1]. Due to the aceleration of the global urbanization in both intensity and area, there is a growing interest in understanding its implications with respect to a broad set of environmental factors including loss of arable land [2], habitat destruction [3], decline in natural vegetation cover and climate at local, regional, and global scales [4]. The conversion of rural areas into urban areas through development is currently occurring at an unprecedented rate in recent human history and is having a marked effect on the natural functioning of ecosystems [5]. Since ecosystems in urban areas are strongly influenced by anthropogenic activities, considerably more attention is currently being directed towards monitoring changes in urban land use/ land cover (LULC) [6]. Such studies are particularly important because the spatial characteristics of LULC are useful for understanding the various impacts of human activity on the overall ecological condition of the urban environment [7]. LULC change due to human activities is currently proceeding more quickly in developing countries than in the developed world, and it has been projected that by the year 2020, most of the world's mega 
cities will be in developing countries [8]. In developing countries, where urbanisation rates are high, urban sprawl is a significant contributor of the land use change. Sprawl generally infers to some type of uncoordinated development with impacts such as loss of agricultural land, open space and ecologically sensitive habitats in and around urban areas due to lack of integrated and holistic approaches in regional planning [9].

In the fast developing countries like India, there is a mass migration of people from rural to urban and also from smaller to bigger urban areas and then to metropolises like Delhi, Bangalore, Mumbai etc. The process of urbanization in India gained momentum with the start of industrial revolution way back in 1970s followed by globalization in 1990s. Forests were cleared, grasslands ploughed or razed, wetlands drained and croplands encroached upon under the influence of expanding cities, yet never as fast as in the last decade [10]. In 1991, there were 23 metropolitan cities in India, which increased to 35 in 2001 [11].Some of the prominent ones are Delhi (13.82 million), Mumbai (11.90 million) and Chennai (4.21 million) with Delhi being the most populated megacity (competing with Mumbai) in the country in terms of human population and vehicular traffic density.

Delhi is one of the many megacities struggling with rapid urbanization and gigantic levels of pollution from industrial, residential and transportation sources [12]. According to Census of India 2001, the population of Delhi has increased by $47.02 \%$ in the decade $1991-2001$ (from 9.4 million in 1991 to 13.82 million in 2001). The up rise in the population of Delhi is mainly due to the migration of people to the capital in search of better living standard. The population of Delhi has reached to 21.7 million in 2009 (increased by 57\% from 2001-2008). After independence, when Delhi witnessed a large influx of migrants, within a very short time the population of Delhi was approximately doubled. To house such a large migrating population, city has expanded in a very unplanned and uncontrolled manner [10]. Such types of unplanned expansions have a direct impact on quality of urban environment affecting the efficiency of the people and their productivity in the overall socio-economic development [13]. In the light of its past experiences and current trends of development, emerging future of Delhi is one of the most important issue gaining focus from the authorities to improve the overall quality of life. Land use which is highly dynamic entity in nature is one of the key parameters to quantify development. The dynamic land use database has a vital application to many diverse fields like Environment, Forestry, Hydrology, Agriculture, Geology, Urban sprawl, etc., [14].

Several studies have demonstrated applicability of Remote sensing (RS) in the area of urban planning, impor- tant RS research has been conducted to date, particularly in urban change analysis and the modeling of growth [9,15-17], LULC evaluation [2,18-21], and urban heatisland research [19,22-24]. In particular, RS-based multitemporal land use change data provide information that can be used for assessing the structural variation of LULC pattern. In addition, accurate and comprehensive land use change statistics are useful for devising sustainable urban and environmental planning strategies $[3,25]$. It is therefore very important to estimate the rate, pattern and type of LULC changes in order to predict future changes in urban development [18]. Thus this study will attempt to identify the spatio-temporal pattern of LULC changes which occurred in Delhi using satellite images periodically from 1997 to 2008 in conjunction with the various master plans from 1962-2021 along with various socio-economic factors such as population, road density, vehicle population, Gross State Domestic Product (GSDP)"etc. to understand the dynamical pattern of urbanization and identify key features for sustainable environmental management of Delhi.

\section{Study Area}

The present study has been carried out on Delhi, the capital city of India located between the $28^{\circ} 24^{\prime} 17^{\prime \prime}$ and $28^{\circ} 53^{\prime} 00^{\prime \prime} \mathrm{N}$ latitudes and $76^{\circ} 45^{\prime} 30^{\prime \prime}$ and $77^{\circ} 21^{\prime} 30^{\prime \prime} \mathrm{E}$ longitudes. Delhi, the National capital Territory situated near the western bank of river Yamuna which spreads over an area of around $1,490 \mathrm{~km}^{2}$ is surrounded by the Himalayas in the North and the Aravali ranges in South West. The hottest months are May and June with temperatures touching $48^{\circ} \mathrm{C}$, whereas, the lowest falls to about $5^{\circ} \mathrm{C}$ at the end of December-January. The monsoon season lasts from July to September with maximum rainfall in the month of July (around $300 \mathrm{~mm}$ ). The total population of Delhi was nearly 0.4 million in 1901, which increased slowly and reached 1.74 million in 1951 (4.35 times in half century) and reached13.78 million in 2001 [11] implying about 34.45 times increase in one century.

\section{Methodology}

In the present study, multi-spectral data acquired from the LISS-III images of IRS (Indian Remote Sensing) satellite of the years 1997, 2000, 2003, 2004, 2005 and 2008 have been utilized for the LULC change detection. Topographic sheets of the study area, obtained from the Survey of India were used for the ground reference. Geometric correction was performed on all the satellite images using the topographic maps of Survey of India of Delhi (1:50000). The images were geo-referenced by using well scattered ground control points. The satellite data was enhanced before classification using median 
filter in ERDAS Imagine 9.2 for the better quality of the image and to achieve better classification accuracy. All images were geometrically corrected and enhanced using the same method. Based on the fieldwork, a ground truth map was prepared for locating training pixels on the image and around 100 reference data points were collected using a global positioning system (GPS). This GPS information was then overlaid with the satellite image in ERDAS to select the training areas and for accuracy assessment.

In preparing the LULC map, the most crucial step is choosing the LULC classification scheme. Generally, a consideration is that the LULC categories should normally confirm to the standard categories defined by the US Geological Survey [26]. Considering the standard categories as well as the local factors like topography, land use etc., ten separate LULC classes were defined, namely: dense built-up, medium dense built-up, less dense built-up, crop land, fallow land, forest cover, scrub land, sandy areas, deep water bodies and shallow water bodies. All satellite images were then studied using spectral and spatial profiles to make certain the digital numbers (DNs) of different LULC categories prior to classification. Training areas were selected from the reference data and from topo maps. Approximately 100 training sites were used to train the images. A supervised maximum likelihood classification (MLC) algorithm, previously demonstrated to obtain the best results from remotely sensed data if assuming that data follows Gaussian distribution [27], was then applied to each of the satellite image using ERDAS Imagine. The classified images were then analysed to compute the areas under each LULC class as adopted in the LULC scheme. The overall accuracy was assessed by estimating commission and omission errors in the error matrix which is a proportion of correctly and wrongly classified pixels [28]. The change detection was then carried out by comparing the areas under each LULC class of the respective years.

Master plans of Delhi (MPD) 1962, 2001, 2021 prepared by Delhi Development Authority (DDA) [29] were used in conjunction with socio-economic parameters obtained from various sources for interpretational analysis. The linear regression analysis was also carried out for forecasting the total built up area obtained from classified images along with population and GSDP for the 2021 and 2031, which was then compared with the projections done by DDA for the MPD-2021. Based on this analysis, the proposed urbanisation plans are examined and key parameters are identified for sustainable growth of the city.

\section{Results and Discussions}

The detailed classified images depicting the ten different
LULC classes for the years 1997, 2000, 2004 and 2008 are shown in Figure1. It can be seen from Figure 1 that there is a vast distribution of the less dense areas throughout the city in 2008 when compared to 1997 especially in North, North West and South West parts of the city. Medium dense built up areas have spread from the centre of the city to the South-East region. The total built-up area has been found to be expanding in the West, North, North-West, South-West and South parts of the city. The Central and East Delhi remained almost unchanged because they already witnessed urbanization earlier; leaving very less scope for further development. As shown in this figure, there is a significant increase in the less dense built-up area by 180.09 sq.km (12.08\% of the total area) and moderate increase in medium dense built up area by 72.68 sq.km ( $4.87 \%$ of the total area) while a marginal decrease of 1.46 sq.km $(0.1 \%$ of the total area) is reflected in the dense built up area. Figure 2 describes the actual areas of the ten LULC in the years 1997 and 2008 as well as increase or decrease in area of each of these classes during this period. As revealed in this figure the area under the less dense built-up category almost doubled from 208 sq.km to 388 sq.km (180 sq.km) during 1997 to 2008 having an overall increment of $12 \%$ in the total area. Medium dense built-up increased by 72.6 sq.km during this period with an overall increment of $4.87 \%$ of the total area. Thus, there is an overall net increase by 251.18 sq.km (16.87 \%) in built-up area. On the other hand there is a decrease in agricultural area by 146.75 sq.km by combining the decrease in crop and fallow land. There is another significant decrease in wasteland by 80.62 sq.km by combining scrub-land and sandy areas. A major decrease from its 1997 values is observed in waterbodies by 30.83 sq.km which is obtained by combining deep and shallow water bodies. It is worth mentioning that waterbodies had a total area of 58.26 sq. $\mathrm{km}$ in 1997 that got reduced to 27.43 sq. $\mathrm{km}$ in 2008 which is about $52.9 \%$ decrease in a ten year period. Shallow waterbodies now have a dismal presence. The significant change is the decline in area occupied by shallow water bodies by $78 \%$ leaving only 2.83 sq.km in 2008 of 13.11 sq.km in 1998. The net decrease in agricultural land, wasteland and waterbodies together accounts for total decrease of 258.20 sq.km against an increase of 251.18 sq.km of net built-up area. Thus it is obviously clear that increase in built-up area in the city has been on the expense of majorly from the agricultural and waste land together with the shrinking waterbodies. The silverlining here is the balance 7.02 sq. $\mathrm{km}$ of the above increasing and decreasing land use classes which has resulted due to increase in forest cover in the city. In 1997, crop land was the dominant LULC category while in the year 2008 it was the less dense built-up area. As 


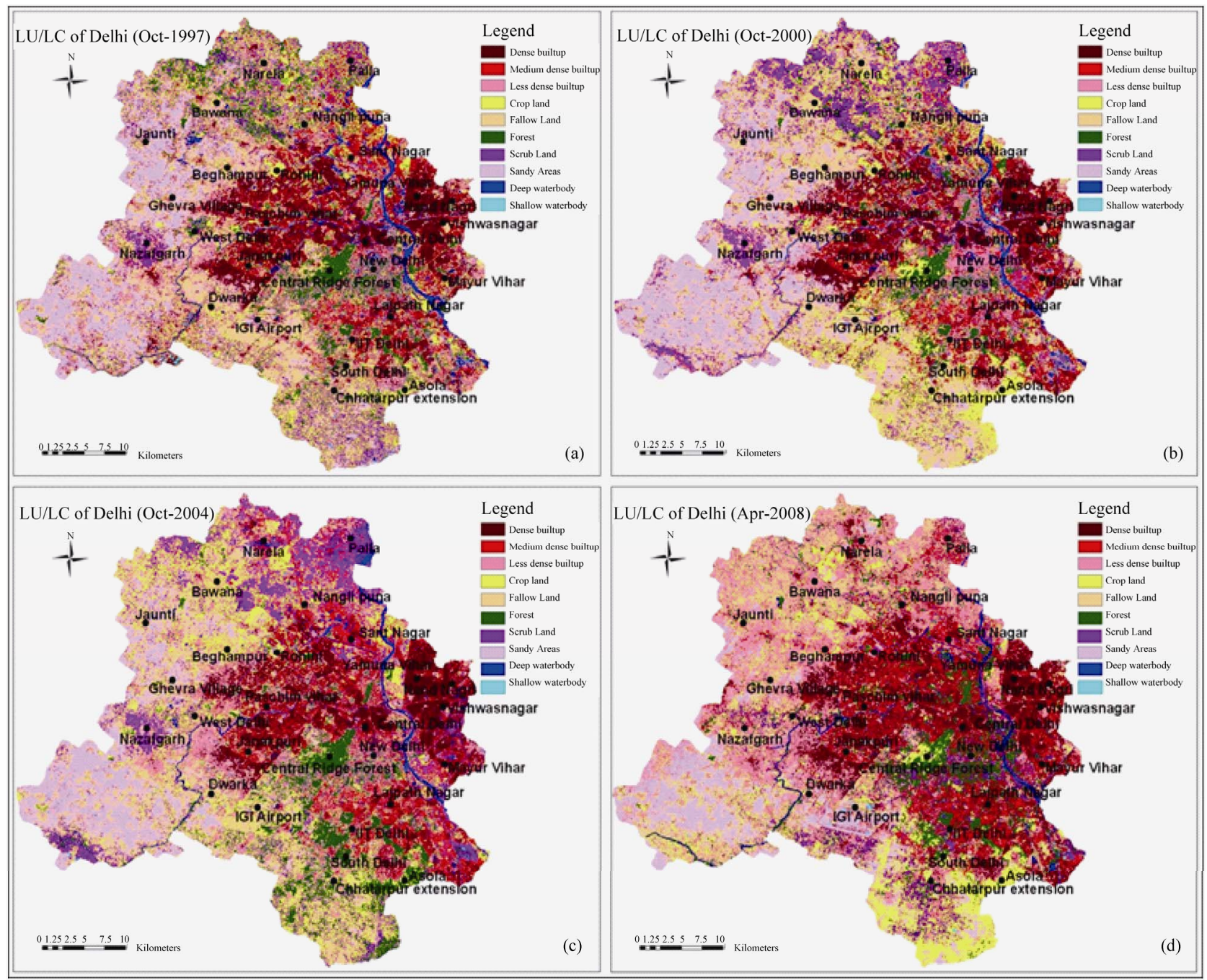

Figure 1. Land use/Land cover distribution over Delhi for the years (a)1997 (b) 2000 (c) 2004 (d) 2008.
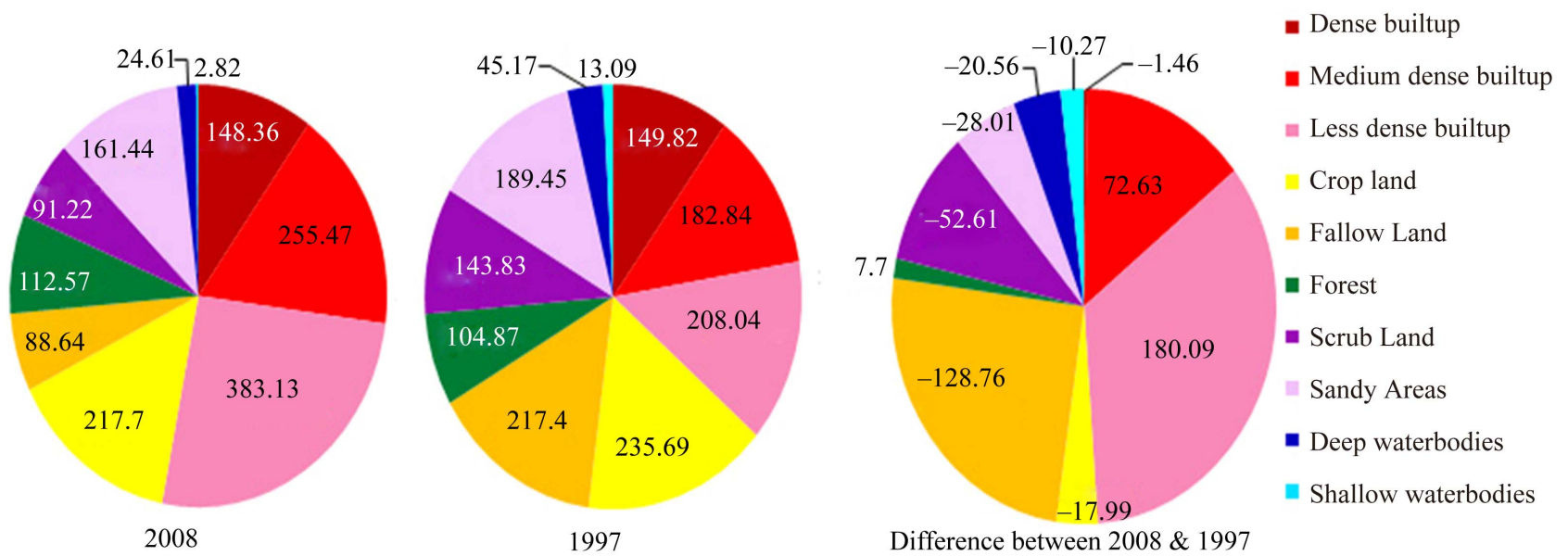

LULC distribution for different classes (sqkm in total area) Total area $=1490 \mathrm{sqkm}$

Figure 2. Land Cover changes for different classes from 1997-2008 (Sq.km in Total area). 
the city developed, the built-up category replaced most of the land classes like sandy areas, fallow landand scrub land. Spatial patterns of LULC changes from the study showed that the city is expanding in all directions except East and Central parts because these areas are already packed with Dense and medium built up areas from a long time. Figure 3 represents the areas where major LULC changes occurred during the study period using change detection method. Most of the LULC classes like fallow land, sandy areas and scrub land were converted into built-up areasnamely Narela, Jaunti, Auchandi, Bawana, Palla, MaidanGarhi etc. in North, North-West and South-West regions.

\section{Change Dynamics of LULC vis-a-vis Urban Growth Parameters}

The increment in the population growth of Delhi has its roots way back in mid of $20^{\text {th }}$ century when India was partitioned after the Independence. Census data indicates that the population of the city was only 0.4 million with $52.76 \%$ of urban population in 1901, increased to 1.74 million with $82.40 \%$ of urban population in 1951 (i.e. increase of 3.3 times from 1901 to 1951). The annual average exponential growth rate of population of Delhi was the highest, 7.3\%, during 1941-1951 due to large scale migration when India partitioned in 1947 (Economic Survey of Delhi, 2007-2008). The population reached to 13.85 million by 2001 (i.e. increase of 8 times from 1951 to 2001) with an annual average growth of $4.1 \%$. After the Independence, the city has dramatically changed in an uncontrolled and unplanned manner to accommodate this increased population. To control this encroachment of undesirable expansion, the city development authorities promulgated the first attempt on comprehensive urban planning for Union Territory of Delhi (UTD), "The Master Plan for Delhi 1962 (MPD-1962)" [29] for the projected population of 47 lakhs ( 1 lakh $=0.1$ million) by 1981 . The plan projections were overshot with the fast pace of population growth by approximately 15 lakhs as the population of Delhi was 62 lakhs in 1981 as shown in Table 1. The master plan was then modified in 1990 for a projected population of 128 lakhs for the year 2001 and named as MPD-2001 [29]. Keeping this projected population in mind, authorities planned the urban expansion up to Rohini in North-West, Narela in North and Dwarka in South-West. However, population again overshot by 10 lakhs and became 138 lakhs in 2001.

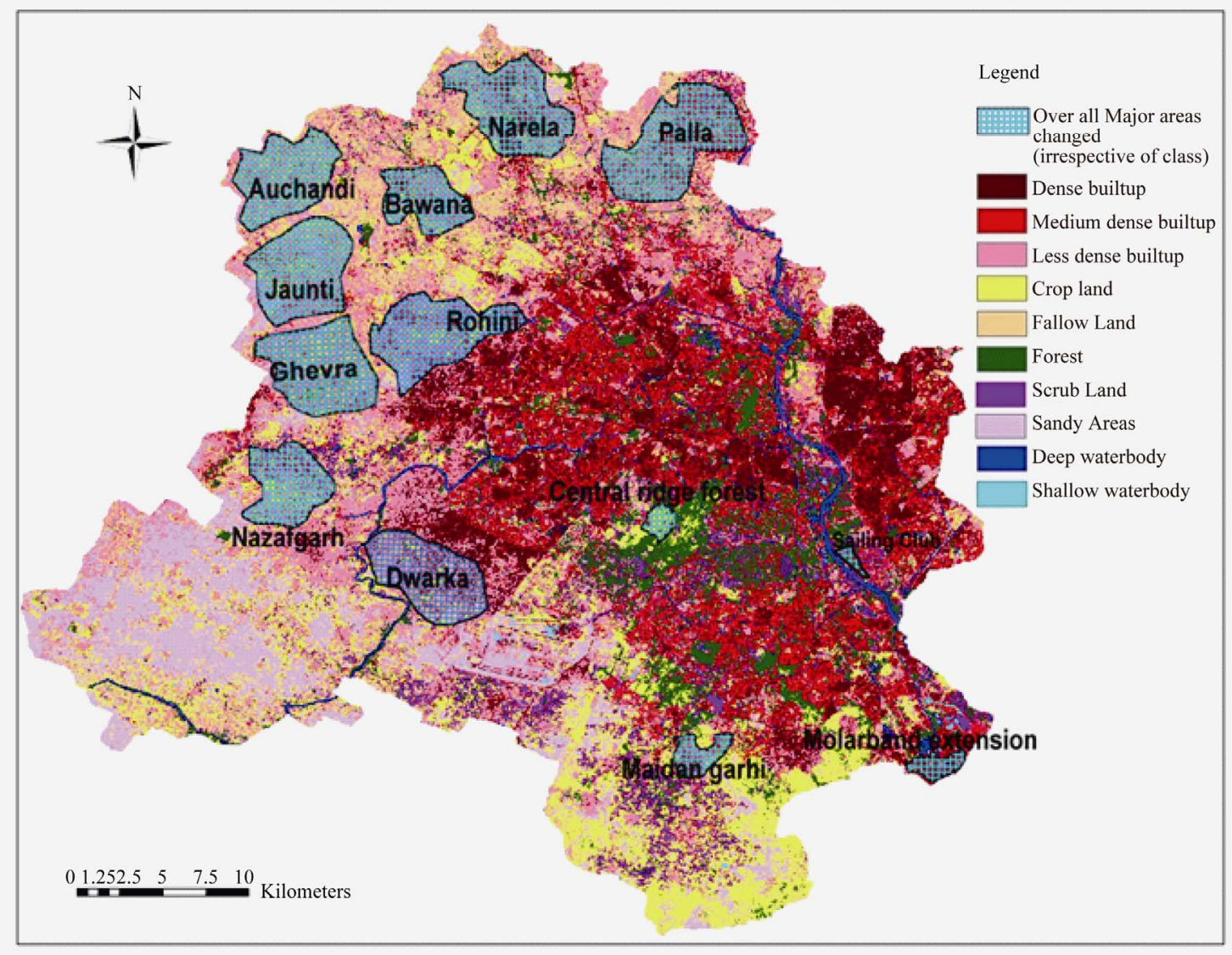

Figure 3. Major interpreted LULC changes during 1997-2008. 
Table 1. Population Changes in National Capital Territory Delhi (in lakhs) [11,29].

\begin{tabular}{|c|c|c|c|c|c|c|}
\hline \multirow{3}{*}{ Year } & \multirow{3}{*}{ Total Population } & \multicolumn{5}{|c|}{ Increase in Population } \\
\hline & & \multirow{2}{*}{ Net Increase } & \multicolumn{2}{|c|}{ Addition by Natural Growth } & \multicolumn{2}{|c|}{ Increase due to Migration } \\
\hline & & & Population & $\%$ & Population & $\%$ \\
\hline 1901 & 4.06 & - & - & & - & \\
\hline 1911 & 4.14 & 0.08 & - & & - & \\
\hline 1921 & 4.89 & 0.75 & - & & - & \\
\hline 1931 & 6.36 & 1.47 & - & & - & \\
\hline 1941 & 9.18 & 2.82 & - & & - & \\
\hline 1951 & 17.44 & 8.26 & - & & - & \\
\hline 1961 & 26.59 & 9.15 & - & & - & \\
\hline 1971 & 40.66 & 14.07 & - & & - & \\
\hline 1981 & 62.20 & 21.54 & 12.0 & 55.71 & 9.54 & 44.29 \\
\hline 1991 & 94.21 & 32.01 & 18.9 & 59.04 & 13.11 & 40.96 \\
\hline 2001 & 138.2 & 43.99 & 26.66 & 60.60 & 17.33 & 39.40 \\
\hline 2011* & 182.39 & 44.19 & 24.2 & 54.76 & 19.99 & 45.24 \\
\hline $2021 *$ & 230 & 47.61 & 24.0 & 50.41 & 23.61 & 49.59 \\
\hline
\end{tabular}

*projected.

In order to accommodate the excess population from Master Plan projections up to 2001 and beyond till 2008, the city was expanding beyond its planned urban extension areas. This had its inevitable implications on development of infrastructure in terms of shelter, including squatter settlements and other facilities such as potable water, sewage system, electricity etc. It can be clearly observed from Figure 1 that the city has swiftly expanded within last decade towards its periphery. It can also be observed that many areas in the outer zone of the Delhi have come up under the category of less dense built up areas/rural settlements during 1997-2008 which were initially fallow/sandy/scrub lands. As can be noted from Figure 1, compared to 1997, the expansion of less dense built up areas/ rural settlements is prominent in 2008.

Keeping in view of the increasing population, Delhi Development Authority (DDA) has proposed a new plan recently, "The Master Plan-2021 (MPD-2021)" [29] to accommodate the growing population. The major part of North-West and South-West regions and some parts in South and North-East Delhi have definite plans for development and are going to be urbanized as a part of Master plan-2021.

LULC changes and urban expansion of Delhi is governed mainly by its geographical location and socioeconomic factors. Although population growth is the primary cause for rapid urbanization, the contribution from other factors such as economic development and physical factors should not be neglected. The physical location of Delhi is main cause of the increasing popula- tion in the form of migration as it is surrounded by populous states like Haryana and Uttar Pradesh. The migration data released by Registrar General of India for the census 2001 indicates that the total population of Delhi of 138.50 lakhs includes 82.04 lakhs from within Delhi and 53.18 lakhs as migrated population from various states in which $43.56 \%$ and $10.26 \%$ of migration is contributing from Uttar Pradesh and Haryana respectively (Table 1). The population of Delhi is expected to be more than 18 million by 2011 [11] with an annual average growth of $4 \%$ and with $93 \%$ of the urban population. It is pointed out that the population of Delhi has already reached 21.7 million in 2009 [30] which is almost more than 4 million than was expected. This increased population had its inevitable implication on increment of built up area. Delhi's population growth is more than double, when compared to the national annual average growth of $1.55 \%$. It is obvious that the increase in this urban population mainly came from the conversion of rural areas into urban expansions and migration of people into Delhi.

Figure 4 represents trends of combined land use category with different statistics like population, vehicles, roads and gross state domestic product (GSDP) of Delhi from 1997-2008. Total built up area and vehicular growth rate are almost identical while road length has less growth rate than vehicular population growth. However a rate of increase in population seems quite similar to the rate of decrease in water bodies. Population and GSDP growth rate is also identical; however GSDP growth rate is significantly higher than the population growth rate 


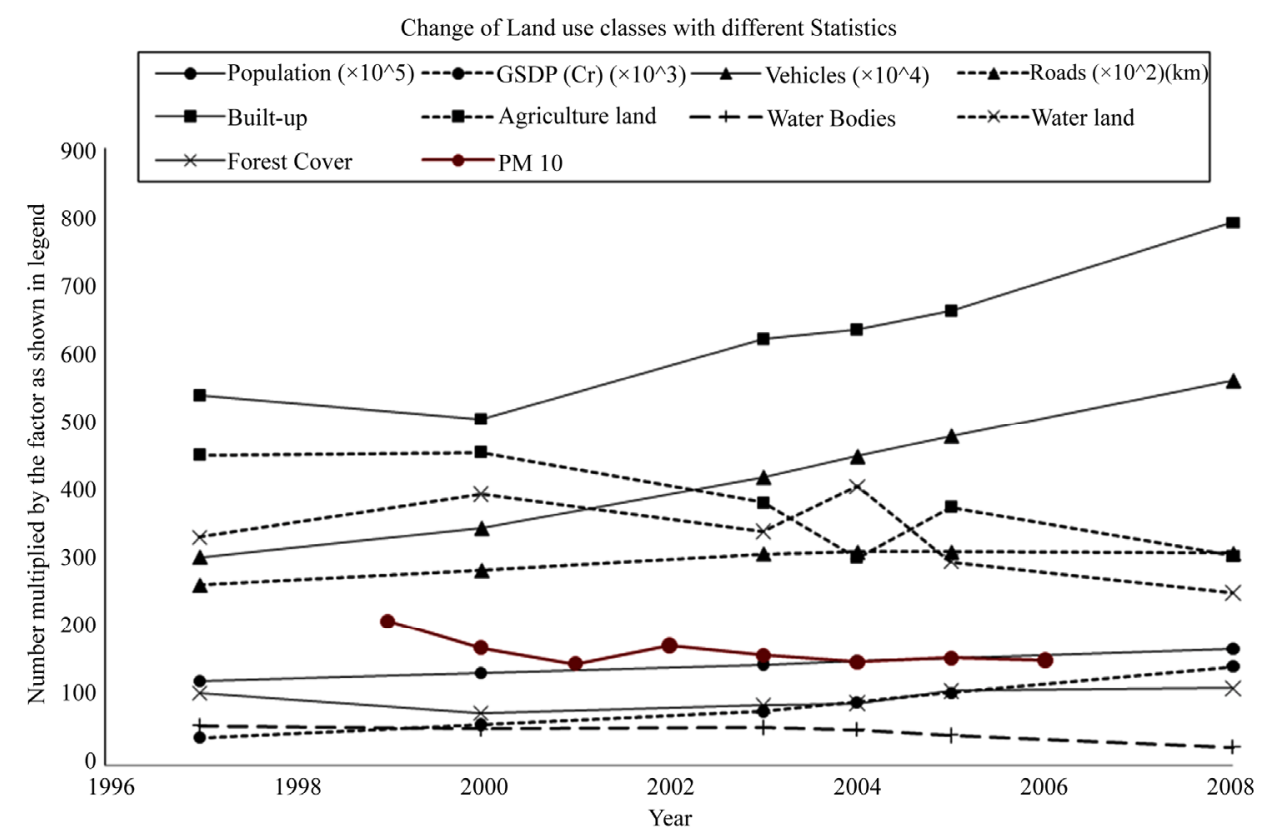

Figure 4. Change of land use classes with different statistics from 1997-2008.

after 2003. It is interesting to note that there is a constant increase in total built up area while there is a constant fall in agriculture land and waste land, however though a sudden decrease in built up area in 2004 and a sudden increase in agriculture land and waste land in the same year seems to be interrelated. In summary, there is an overall decrease in water bodies, waste land and agricultural land after 2000 and at the same time there is also an overall increase in the total built up area after 2000 indicating interrelationship between the two that can be explored in future.

A regression analysis was performed between population growth, GSDP and total built-up area to know the dependency of one over another. A significant positive relationship was observed between built-up area and population growth $\left(r^{2}=0.86, p=0.05\right)$ while another positive relationship is also observed between built-up area and $\operatorname{GSDP}\left(r^{2}=0.92, p=0.05\right)$. Figure 5 shows year wise (1997-2008) total built-up area, population and GSDP where all of these are fitting well to the linear regression relationships. Further, total built-up area, population and GSDP for the years 2021 and 2031 have been projected using the corresponding liner regression relationships as shown in Table 2.

These values have been compared with values from the master plan-2021 and they are found to be quite close. The total built up area in 2021 according to the master plan is going to be around $978 \mathrm{~km}^{2}$, this means that $66 \%$ of the total area is going to be the built up area when it is compared to $53 \%$ in 2008 . If the population is growing at the same rate by 2031 , the projected values show that
$85 \%$ of the total area is going to be built up class in order to accommodate this population growth. This means that other LU-LC classes will become insignificant except built up area.

\section{Conclusions and Recommendations}

The present study has assessed LULC changes and the effect of urbanization on the LULC classes in Mega city Delhi using RS data in conjunction with Master Plans and various socio-economic parameters. The results showed that the LULC classes of Delhi have experienced rapid changes particularly in built-up category. Built-up area of Delhi witnessed an overall increment of $17 \%$ of the total area i.e. from $540.5 \mathrm{~km}^{2}$ to $791.6 \mathrm{~km}^{2}$ during the study period 1997 to 2008 which mainly came from agriculture land and waste land. The increment in forest cover of $0.5 \%$ is very small when considering the increment in built up category to $17 \%$. More efforts have to be made in increasing or preserving the green cover. The results also showed significant decrease in crop and fallow land. It is suggested that urban expansion shall be diverted towards waste land or sandy areas in place of productive agricultural lands. The waterbodies had a total area of 58.26 sq. km in 1997 which got reduced to 27.43 sq.km in 2008 which is about $52.9 \%$ decrease in a ten year period especially shallow water bodies decreased by 10.27 sq.km leaving only 2.82 sq.km. There is an immmidate need to take action in reviving the waterbodies in Delhi as ground water contributes to substantial quantity of supply in newly developed areas mainly because of the insufficiency of the Yamuna water 


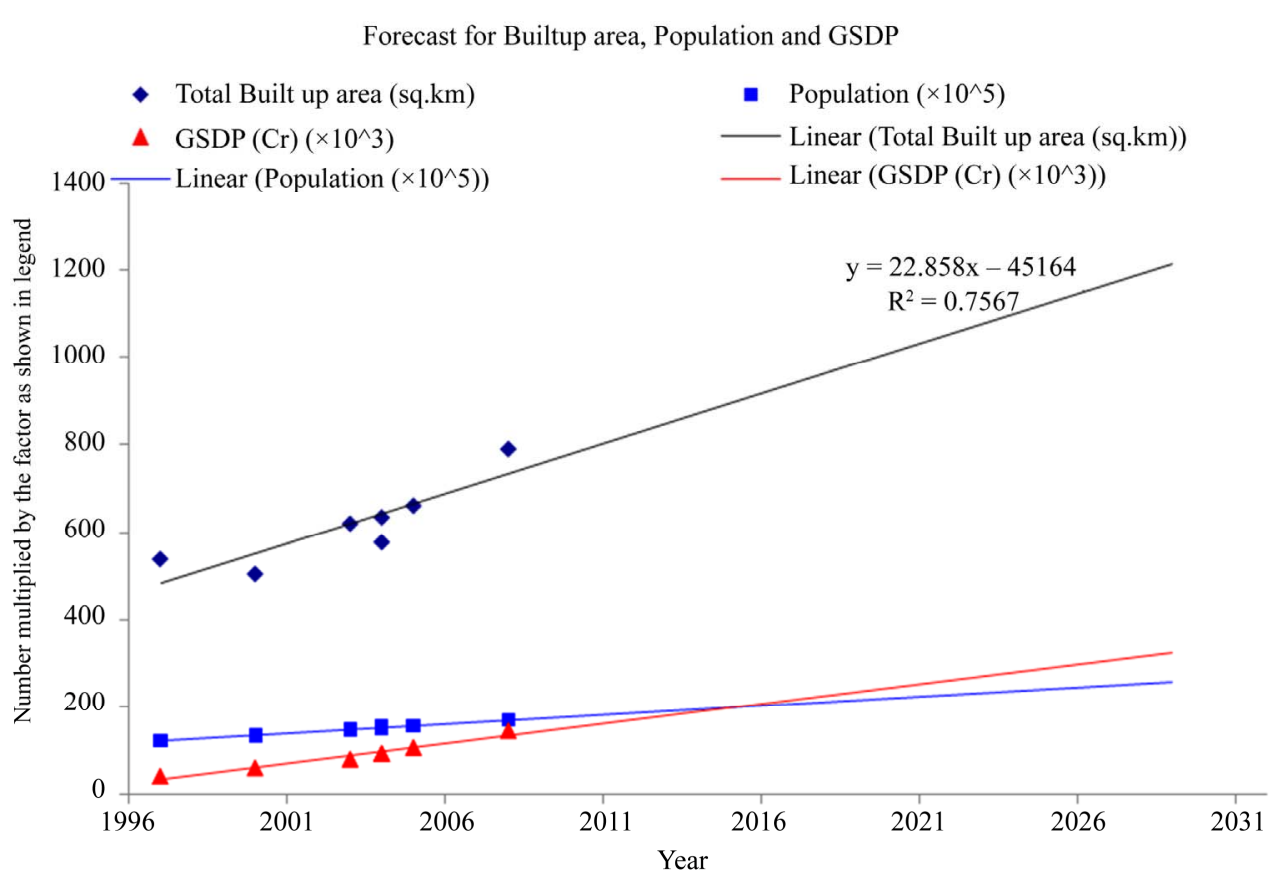

Figure 5. Forecast for built up area, population and GSDP of Delhi.

Table 2. Projections of various urban parameters.

\begin{tabular}{ccccc}
\hline & \multirow{2}{*}{$\mathbf{2 0 0 8}$} & \multicolumn{2}{c}{$\mathbf{2 0 2 1}$} & \multirow{2}{*}{$\mathbf{2 0 3 1}$} \\
\cline { 3 - 4 } & & this study projections & MPD-2021 projections & \\
\hline Total Built up area (Sq.km) & 791.637 & 1015.85 & 977.90 & 1244.35 \\
Population $\left(\times \mathbf{1 0}^{5}\right)$ & 169.55 & 249.68 & 225 & 340.48 \\
GSDP $(\mathbf{C r})\left(\times \mathbf{1 0}^{\mathbf{3}}\right)$ & 143.912 & 224.838 & -- & 267.618 \\
\hline
\end{tabular}

share for Delhi. Authorities have to identify the locations where ground water recharge can be achieved and those recharge areas needs to conserved and preserved for the sustainable management of ground water in Delhi. Another implication to preserve water is through strict implementation of use of rain water harvesting. Currently the annual rain water harvesting potential has assessed to be around 900 billion liters annually [29], against the present requirements of nearly 1511 billion liters annually. Even if $50 \%$ of rain water harvesting is achieved, it would easily be close to the present deficiency of 430 billion liters annually. Hence, authorities need to effectively increase public awareness, improve regulations and implementation. The Yamuna River is found to be watered down from either side of its banks. Over the years; encroachments on the river banks, backlog in sanitation and waste water management services, have resulted in the dwindling of water flow in the river with extremely high levels of pollution which is another major concern to be alerted. One of the contributory factors to the flow of untreated sewage into river Yamuna is the slum clusters that have come up unauthorized on both banks of river Yamuna. The banks of river can be restored by clearing slums and occupied areas. A green belt or plantations can be formed on both banks which provide substantial environmental benefits. These plantations also help to control erosion, reduce salinity and improve water quality. Another tormenting issue of concern is pollution caused by increasing vehicular population and industries. Despite of various implications and initiative measures taken from past years, like implementation of CNG, EURO-IV, Metro as public transport etc. the pollution levels have again shown an increasing trend particularly for Respirable Particulate Matter and Nitrogen Oxides. Public transportation planning must, therefore, drive the future policy to aim to make public transport a mode for personal vehicle owners and users through a mix of incentives and disincentives. Though some of these suggestions have been already included in MPD-2021, authorities have to make concerted efforts for strict norm for following these regulations. The builtup area is expected to increase from $53 \%$ in 2008 to 66 $\%$ and $85 \%$ in 2021 and 2031 respectively to accommodate increasing population. This requires a holistic ap- 
proach to urban development in order to appropriately preserve the areas of various land-use classes. Moreover, the actual population is turning out to be more than the projected population for this city e.g., the present population has already increased to 21.7 million in 2009 [30] which is more than 4 million than that of the projected population of 18 million in 2011 [11]. This requires more conservative urban planning by the authorities.

\section{Acknowledgements}

The financial support extended by Indian Space Research Organization (ISRO) through their RESPOND programme for carrying out this study is thankfully acknowledged. Authors pay homage to Dr. S. K. Pathan (second author) who passed away untimely few days after the acceptance of this paper. Fellow workers shall always remember him as a highly dedicated scientist instilling inspiration to excel as also a noble kind hearted soul.

\section{REFERENCES}

[1] United Nations Population Fund, "The State of World Population 2007: Unleashing the Potential of Urban Growth," United Nations Publications, Chapter 1, 2007.

[2] E. Lopez, G. Bocco, M. Mendoza and E. Duhau, "Predicting Land Cover and Land Use Change in the Urban Fringe a Case in Morelia City, Mexico," Landscape and Urban Planning, Vol. 55, No. 4, 2001, pp. 271-285.

[3] H. Alphan, "Land Use Change and Urbanization in Adana, Turkey," Land Degradation and Development, Vol. 14, No. 6, 2003, pp. 575-586. doi:10.1002/1dr.581

[4] N. B. Grimm, J. M. Grove, S. T. A. Pickett and C. L. Redman, "Integrated Approach to Long-Term Studies of Urban Ecological Systems," Bioscience, Vol. 50, No. 7, 2000, pp. 571-584.

doi:10.1641/0006-3568(2000)050[0571:IATLTO]2.0.CO ;2

[5] B. L. Turner, "Local Faces, Global Flows: The Role of Land Use and Land Cover in Global Environmental Change," Land Degradation and Development, Vol. 5, 1994, pp. 71-78. doi:10.1002/ldr.3400050204

[6] D. A. Stow and D. M. Chen, "Sensitivity of Multi-Temporal NOAA AVHRR Data of an Urbanizing Region to Land Use/Cover Changes and Misregistration," Remote Sensing of Environment, Vol. 80, 2002, pp. 297-307. doi:10.1016/S0034-4257(01)00311-X

[7] A. G. O. Yeh and X. Li, "Economic Development and Agricultural Land Loss in the Pearl River Delta, China," Habitat International, Vol. 23, 1999, pp. 373-390. doi:10.1016/S0197-3975(99)00013-2

[8] Sustainable Development Unit, South Asia Region, "Dhaka: Improving Living Conditions for the Urban Poor," Report No. 35824-BD, 2007.

[9] H. S. Sudhira and T. V. Ramachandra, "Characterizing Urban Sprawl from Remote Sensing Data and Using Landscape Metrics," 10th International Conference on
Computers in Urban Planning and Urban Management, PR Brazil, 2007. http://eprints.iisc.ernet.in/11834/

[10] A. Rahman, "Application of Remote Sensing and GIS Techniques for Urban Environmental Mamangement and Sustainable Development of Delhi, India," Applied Remote Sensing for Urban Planning, Governance and Sustainability, Springer-Verlag Publishers, New York, 2007, pp. 165-197.

[11] Census of India, "Provisional Population Totals," Office of Registrar General of India, Government of India, New Delhi, 1991 and 2001. http://censusindia.gov.in/

[12] M. Mohan, Lalit Dagar and B. R. Gurjar, "Preparation and Validation of Gridded Emission Inventory of Criteria Air Pollutants and Identification of Emission Hotspots for Megacity Delhi," Environmental Monitoring and Assessment, Vol. 130, 2007, pp. 323-339. doi:10.1007/s10661-006-9400-9

[13] M. Netzband and A. Rahman, "Urban Remote Sensing for a Fast-Growing Megacity: Delhi, India," SPIE International Society Advancing an Interdisciplinary Approach to the Science and Application of Light, Berlin, Germany, 2007. http://spie.org/x17987.xml

[14] T. V. Ramchandra and U. Kumar, "GRDSS for Land Use, Land Cover Dynamics Analysis," Proceedings of the FOSS/GRASS Users Conference, Bankok, Thiland, 2004.

[15] P. J. Hardin, M. W. Jackson and S. M. Otterstrom, "Mapping, Measuring and Modeling Urban Growth," Geospatial technologies in urban environments: Policy, practice and pixels, 2007, pp. 141-176.

[16] M. K. Ridd and J. J. Liu, "A Comparison of Four Algorithms for Change Detection in an Urban Environment," Remote Sensing of Environment, Vol. 63, 1998, pp. 95100. doi:10.1016/S0034-4257(97)00112-0

[17] C. Weber and A. Puissant, "Urbanization Pressure and Modeling of Urban Growth: Example of the Tunis Metropolitan Area," Remote Sensing of Environment, Vol. 86, 2003, pp. 341-352. doi:10.1016/S0034-4257(03)00077-4

[18] A. M. Dewan and Y. Yamaguchi, "Land Use and Land Cover Change in Greater Dhaka, Bangladesh Using Remote Sensing to Promote Sustainable Urbanization," Applied Geography, Vol. 29, 2009, pp. 390-401. doi:10.1016/j.apgeog.2008.12.005

[19] J. Xiao, Y. Shen, J. Ge, R. Tateishi, C. Tang, Y. Liang and Z. Huang, "Evaluating Urban Expansion and Land Use Change in Shijiazhaung, China by Using GIS and Remote Sensing," Landscape and Urban Planning, Vol. 75, 2006, pp. 69-80. doi:10.1016/j.landurbplan.2004.12.005

[20] X. Yang and C. P. Lo, "Using a Time Series of Satellite Imagery to Detect Land Use and Cover Changes in the Atlanta, Georgia," International Journal of Remote Sensing, Vol. 23, No. 9, 2002, pp. 1775-1798. doi:10.1080/01431160110075802

[21] F. Yuan, "Land-Cover Change and Environmental Impact Analysis in the Greater Mankato area of Minnesota Using Remote Sensing and GIS Modeling," International Journal of Remote Sensing, Vol. 29, No. 4, 2008, pp. 1169- 
1184. doi:10.1080/01431160701294703

[22] S. Kato and Y. Yamaguchi, "Analysis of Urban HeatIsland Effect Using ASTER and ETM + Data: Separation of Anthropogenic Heat Discharge and Natural Heat Radiation from Sensible Heat Flux," Remote Sensing of Environment, Vol. 99, No. 1-2, 2005, pp. 44-54.

[23] M. L. Imhoff, P. Zhang, E. Robert Wolfe and L. Bounoua, "Remote Sensing of the Urban Heat Island Effect across Biomes in the Continental USA," Remote Sensing of Environment, Vol. 114, 2010, pp. 504-513. doi:10.1016/j.rse.2009.10.008

[24] Q. Weng, "A Remote Sensing-GIS Evaluation of Urban Expansion and Its Impact on Surface Temperature in the Zhujiang Delta, China," International Journal of Remote Sensing, Vol. 22, No. 10, 2001, 1999-2014.

[25] R. Verma, K. Sangeeta Kumari and R. K.Tiwary, “Application of Remote Sensing and GIS Technique for Efficient Urban Planning in India," Geomatrix Conference Proceedings, IIT Bombay, 2009.

http://www.csre.iitb.ac.in/ csre/conf/wp-content/uploads/ fullpapers/OS4/OS4_13.pdf
[26] P. Roudgarmi, M. Monavari, J. Feghhi, J. Nouri and N. Khorasani, "Environmental Impact Prediction Using Remote Sensing Images," Journal of Zhejiang University Science A, Vol. 9, No. 3, 2008, pp. 381-390. doi:10.1631/jzus.A072222

[27] P. V. Bolstad and T. D. Lillesand, "Rapid Maximum Likelihood Classification," Photogrammetric Engineering \& Remote Sensing, Vol. 57, 1991, pp. 67-74.

[28] G. H. Rosenfield and K. Fitzpatirck-Lins, "A Coefficient of Agreement as a Measure of Thematic Classification Accuracy," Photogrammetric Engineering \& Remote Sensing, Vol. 52, No. 2, 1986, pp. 223-227.

[29] Delhi Development Authority, "The Master Plan for Delhi-1962, 2001 \& 2021,"

http://dda.org.in/planning/mpd-1962.htm http://dda.org.in/planning/mpd-2001.htm http://dda.org.in/planning/mpd-2021.htm

[30] Population Division, Department of Economic and Social Affairs, United Nations, "World Urbanization Prospects: The 2009 Revision," 2010.

http://esa.un.org/unpd/wup/wall-chart_1.htm 